\title{
Broad inclusion leads to maximal value - examining travel costs associated with clinical trial participation
}

\author{
Hala T. Borno ${ }^{1}$ (1) ', Sylvia Zhang ${ }^{2}$, Elena Nieves ${ }^{3}$, Dana Dornsife ${ }^{4}$, Robert Johnson ${ }^{4}$, Darcy Spicer ${ }^{3}$, Tracy K. Lin $^{5}$ \\ ${ }^{1}$ Division of Hematology/Oncology, Department of Medicine, University of California, San Francisco, San Francisco, CA, USA; Helen Diller Family \\ Comprehensive Cancer Center, San Francisco, CA, USA, 2 Division of Hematology/Oncology, Department of Medicine, University of California, San \\ Francisco, San Francisco, CA, USA, ${ }^{3}$ Department of Medicine, Division of Hematology/Oncology, University of Southern California, Los Angeles, CA, \\ USA, ${ }^{4}$ Lazarex Cancer Foundation, Danville, CA, USA, ${ }^{5}$ Institute for Health \& Aging, Department of Social and Behavioral Sciences, University of \\ California San Francisco, San Francisco, CA, USA
}

Keywords: financial toxicity, diversity and inclusion, clinical trial participation, social good, clinical trials, financial reimbursement program, recruitment science

https://doi.org/10.53876/001c.27061

\section{International Journal of Cancer Care and Delivery}

\begin{abstract}
Acts of social good, like jury service and voting, lead to distributive societal benefits and often come with protections to ensure that everyone can participate. Clinical trial participation is an act of social good, yet it lacks protections or benefits and comes at great personal cost. In this current study, we assessed the indirect costs associated with cancer clinical trial participation among patients enrolled in therapeutic cancer clinical trials at two National Cancer Institute-Designated Comprehensive Cancer Centers as part of a multi-institutional IMPACT (Improving Patient Access to Cancer Clinical Trials) program from January 2018 to August 2020. A total of 258 patients received financial reimbursement during the IMPACT program period. The median (interquartile range, IQR) reimbursed total amount (including all cost categories possible) in US dollars is $\$ 378$ (1123); the median reimbursed amount for each category is $\$ 0(0)$ as patients typically do not request for reimbursement in all categories. The median amount of requested entries was $\$ 713(1,824)$ for lodging, $\$ 248$ (902) for ground transportation, \$208 (373) for gas/ parking/tolls, $\$ 1080$ (2105) for patient flight, and \$1,001 (1793) for companion flight. Average cost per patient attributable to lodging was $\$ 342$ (standard deviation, $S D=1081$ ), ground transportation was $\$ 277$ ( $\mathrm{SD}=843$ ), gas/parking/tolls was $\$ 410(\mathrm{SD}=634$ ), companion flight was $\$ 70(\mathrm{SD}=477)$, and patient flight was $\$ 76(\mathrm{SD}=506)$. Our analysis of costs demonstrates that clinical trial participants incur indirect costs to engage in clinical trials, and these costs vary by institution. These data support the notion that clinical trial participants should receive the same protections and benefits that government and employers offer other social goods such as voting or jury service.
\end{abstract}

\section{INTRODUCTION}

Acts of social good, like jury service and voting, lead to distributive societal benefits and often come with protections to ensure that everyone can participate. Clinical trial participation is an act of social good, yet it lacks protections or benefits and comes at a high personal cost to the participant.(Chino and Zafar 2019) In this current study, we assessed the indirect costs associated with cancer clinical trial participation among patients enrolled in therapeutic cancer clinical trials at two National Cancer Institute-Designated Comprehensive Cancer Centers as part of a multi-institu- tional IMPACT (Improving Patient Access to Cancer Clinical Trials) program.

\section{METHODS}

The IMPACT program provided financial reimbursement for indirect costs associated with cancer treatment clinical trial participation from January 2018 to August 2020 at the University of California San Francisco and University of Southern California. Patients with a household income $\leqslant 700 \%$ of 2018 Health and Human Services poverty guidelines were eligible for reimbursement. Receipts and a monthly travel

\footnotetext{
a Corresponding author:

Hala T. Borno, MD

Assistant Professor of Medicine

Division of Hematology/Oncology

Department of Medicine, University of California San Francisco, CA

Hala.borno@ucsf.edu

415-443-4605
} 

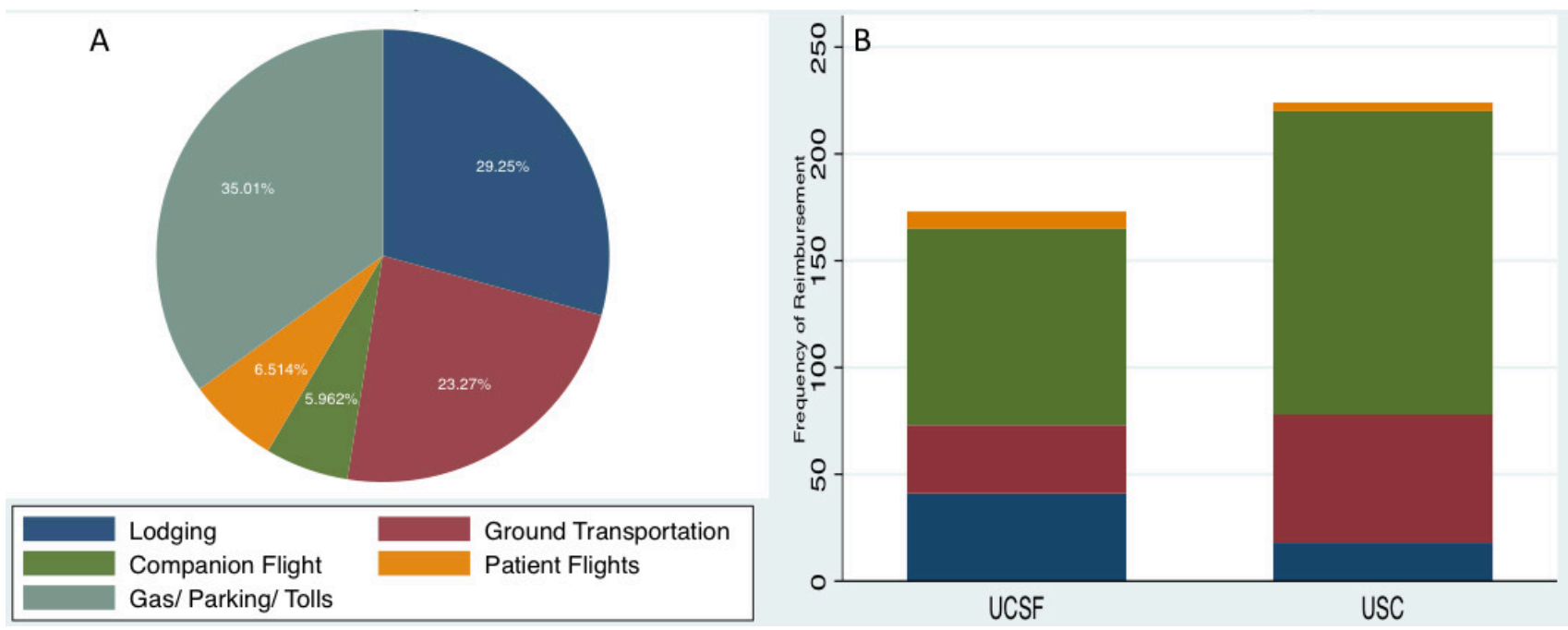

Figures 1A. Reimbursement amount per category; 1B. Frequency of reimbursement per category per site

log were submitted directly by email, postal mail, or fax to a centralized reimbursement processor at Lazarex Cancer Foundation. Receipts were categorized as lodging, ground transportation, gas/parking/tolls, or flight (companion/patient). We generated descriptive statistics on costs and employed a Kruskal-Wallis (K.W.) equality-of-populations rank test to compare institutional differences in reimbursement patterns.

\section{RESULTS}

A total of 258 patients received financial reimbursement during the IMPACT program period. The median (interquartile range, IQR) reimbursed total amount (including all cost categories possible) in U.S. dollars is $\$ 378$ (1123); the median reimbursed amount for each category is $\$ 0(0)$ as patients typically do not request for reimbursement in all categories. The median amount of requested entries was $\$ 713$ $(1,824)$ for lodging, $\$ 248$ (902) for ground transportation, \$208 (373) for gas/ parking/ tolls, \$1080 (2105) for patient flight, and \$1,001 (1793) for companion flight. Average cost per patient attributable to lodging was $\$ 342$ (standard deviation, $\mathrm{SD}=1081$ ), ground transportation was $\$ 277(\mathrm{SD}=843)$, gas/parking/tolls was $\$ 410$ (SD=634), companion flight was $\$ 70$ ( $\mathrm{SD}=477)$, and patient flight was $\$ 76(\mathrm{SD}=506)$. As shown in Figure 1A-B, among a total of 411 reimbursed items, the majority reimbursed amount was for gas/parking/ tolls ( $\mathrm{n}=235$, 35\% total amount) and ground transportation ( $\mathrm{n}=93,29 \%$ total amount). Institutional differences were observed in reimbursement cost categories of lodging and gas/parking/tolls (Table 1).

\section{DISCUSSION}

In the context of the current COVID-19 pandemic, the distributive benefits of clinical trial participation could not be more apparent; the development of treatments and safe vaccines provides massive social and economic benefits where the beneficiaries are unknown and widely distributed. Yet, despite these distributive societal benefits, clinical trial participants continue to bear high costs that are frequently overlooked and unaddressed. Our analysis of costs demonstrates that clinical trial participants incur indirect costs in order to engage in clinical trials, and these costs vary by institution.

These data support the notion that clinical trial participants ought to receive the same protections and benefits that government and employers offer other social goods such as voting or jury service. Several state laws require that employers must allow time off for their employees to vote, a small step to ensure government is genuinely representative of constituents.(“Time off to Vote' Notices,” n.d.) Jurors who are summoned for jury service receive an attendance payment from the government and reimbursement for travel.(United States Courts, n.d.) For clinical trial participants, no standardized reimbursement is provided to address indirect costs or the economic opportunity loss of missed work to attend trial visits. As a result, patients of the lowest socioeconomic status experience the greatest hardship in accessing trials.(Borno et al. 2018) Given that broad inclusion among clinical participants is essential for maximal value, reimbursement ought to be considered standard practice to offset the indirect costs patients currently face. 
Table 1. Institutional Comparison of Reimbursement Patterns

\begin{tabular}{|l|l|l|l|l|}
\hline \multirow{2}{*}{ Category } & \multicolumn{2}{|l|}{ Rank Sum } & \multirow{2}{*}{$\chi^{\mathbf{2}}$} & \multirow{2}{*}{ P-value } \\
\cline { 2 - 5 } & UCSF (n=99) & USC (n=159) & & \\
\hline Lodging & 14935.00 & 18218.00 & 15.695 & 0.0001 \\
\hline Ground Transportation & 12203.00 & 20950.00 & 0.575 & 0.4482 \\
\hline Gas/Parking/Tolls & 14905.50 & 18247.50 & 15.293 & 0.0001 \\
\hline Flights & 13086.00 & 20067.00 & 0.588 & 0.4430 \\
\hline Total Amount & 15018.50 & 18134.50 & 16.858 & 0.0001 \\
\hline
\end{tabular}

\section{DISCLOSURES/CONFLICTS OF INTEREST}

Borno receives grant support from the Lazarex Cancer Foundation.

\section{ACKNOWLEDGMENTS}

Borno is funded by the Prostate Cancer Foundation. Borno, Lin, Nieves, Zhang, and Spicer are funded by Lazarex Cancer Foundation.

Submitted: July 21, 2021 PDT, Accepted: August 01, 2021 PDT 


\section{REFERENCES}

Borno, H. T., L. Zhang, A. Siegel, E. Chang, and C. J. Ryan. 2018. "At What Cost to Clinical Trial

Enrollment? A Retrospective Study of Patient Travel Burden in Cancer Clinical Trials.” Oncologist, April. ht tps://doi.org/10.1634/theoncologist.2017-0628.

Chino, F., and S. Y. Zafar. 2019. "Financial Toxicity and Equitable Access to Clinical Trials.” Am Soc Clin Oncol Educ Book 39: 11-18. https://doi.org/10.1200/EDBK_1 $\underline{00019}$.
“'Time off to Vote' Notices.” n.d. https://www.sos.ca.go v/elections/time-vote-notices.

United States Courts. n.d. https://www.uscourts.gov/ser vices-forms/jury-service/juror-pay. 